in vivo $35: 1393-1399(2021)$

doi:10.21873/invivo.12391

Review

\title{
A Potential Pathogenic Link Between Cancer of Female Reproductive System and Infertile Women Treated With Assisted Reproduction Techniques
}

\author{
MICHAIL DIAKOSAVVAS ${ }^{1}$, ZACHARIAS FASOULAKIS ${ }^{1}$, THOMAS NTOUNIS ${ }^{1}$, \\ ANTONIOS KOUTRAS ${ }^{2}$, KYVELI ANGELOU ${ }^{1}$, GEORGIOS TSATSARIS ${ }^{2}$, \\ ATHANASIOS SYLLAIOS ${ }^{3}$, NIKOLAOS GARMPIS ${ }^{3}$ and EMMANUEL N. KONTOMANOLIS ${ }^{2}$ \\ ${ }^{1}$ First Department of Obstetrics and Gynecology, National and Kapodistrian University of Athens, Athens, Greece; \\ ${ }^{2}$ Department of Obstetrics and Gynecology, Democritus University of Thrace, Komotini, Greece; \\ ${ }^{3}$ First Department of Surgery, Laiko General Hospital of Athens, Athens, Greece
}

\begin{abstract}
Prevention and treatment of infertility remains a priority for developed countries where a large proportion of women undergo in vitro fertilization (IVF) after ovarian stimulation. Latest data suggest that, in the USA alone, almost eight million women of fertile age will have sought medical advice for fertility problems by 2025. However, over the last years, attention has been increasingly focused, and questions have risen, on the long-term health effects in women who underwent assisted reproductive technologies (ARTS). Since the emergence of ART, reports highlight a possible connection of ovarian stimulation and several types of gynaecological cancer, including ovarian, endometrial and cervical types, but due to limited scientific evidence, such a speculation is still under investigation. The objective of this review is to summarize the latest data of ovarian hyperstimulation and IVF, associated with the risk of gynecological tract cancer development.
\end{abstract}

Over the last years, infertility has emerged as one of the major diseases of young couples, since it is considered the third most common health issue, only behind malignancies and cardiovascular diseases (1). Nowadays, an increasing number of people, almost $10 \%$ of the population or one in seven

This article is freely accessible online.

Correspondence to: Nikolaos Garmpis, First Department of Surgery, Laiko General Hospital of Athens, Agiou Thoma Str. 17, 11527 Athens, Greece. Tel: +30 6944567622, e-mail: antoniskoy@yahoo.gr

Key Words: Assisted reproduction technology, fertility drugs, gynecological cancer, ovarian, endometrial, review. couples, mostly in developed countries, are facing difficulties in conceiving naturally and are seeking fertility therapies through assisted reproduction technologies (ARTs) (1-4). The major factor contributing to this rise is the delaying attempts to parenting due to the desire for a successful career and other socioeconomic factors, such as the financial and educational levels of people trying to conceive $(1,5)$.

Since the begging of ART utilization, an ongoing debate on the long-term effects of fertility treatments and mainly their potential effect on subsequent cancer risk, has existed among members of the scientific community $(5,6)$. The prevalence of infertility is affected by a number of conditions, such as genetic, environmental, nutritional and physiological with the main risk factors predisposing to subfertility being obesity, anovulation, excessive smoking, endometriosis, and nulliparity $(1,7)$. The same conditions, which in the recent years are on the rise, are simultaneously independent risk factor of carcinogenesis (7). Moreover, ARTs utilize medications and procedures that cause ovarian trauma via the oocyte retrieval and induce multiple ovulations, hence having as an outcome an increase in sex hormone levels (estrogen, progesterone and gonadotropins) $(1,2)$. Taking into consideration the fact that female reproductive malignancies and breast cancers are in many cases hormone-dependent, an association between ARTs and cancer seems intuitive (3) (Table I).

The aim of this review is to investigate the safety of the fertility treatment modalities, both in the short and long-term, and to examine whether the argument of correlation between carcinogenesis and assisted reproduction techniques is legitimate (Figure 1). Furthermore, our goal, is to determine whether this risk is justifiable given the significant desire of a woman to achieve a pregnancy and give birth. 
Table I. Infertility and gynecologic risk factors.

\begin{tabular}{cc}
\hline Infertility & Gynecologic cancer \\
\hline $\begin{array}{c}\text { Uterine or cervical abnormalities } \\
\text { Fallopian tube damage or blockage } \\
\text { Endometriosis }\end{array}$ & Age \\
$\begin{array}{c}\text { Primary ovarian insufficiency } \\
\text { Cancer }\end{array}$ & Family history \\
Diabetes \\
Nulliparity (including Infertility) \\
Late menopause \\
Immunosuppression
\end{tabular}

STD: Sexual transmitted diseases; PCOS: polycystic ovarian syndrome.

\section{Methods}

An extensive search of the published literature was conducted using the following key terms: Assisted Reproduction Technology, In-Vitro Fertilization, Infertility, Gynecological cancer, Ovarian, Endometrial, Cervical, malignancy and carcinomatosis. The Medline/PubMed, and the Cochrane Library Database of Systematic Reviews were thoroughly searched for our primary search.

\section{Ovarian Cancer}

Invasive ovarian cancer. Although the research studies investigating the connection amongst the risk surrounding the ovarian cancer and medication of fertility utilization show mixed outcomes, most studies do not demonstrate a significant increase in risk $(5,6,8-16)$. In the 1990s, two studies found a relationship between fertility medication utilization and ovarian cancer but were limited by specific disease characteristics, such as low prevalence and late-onset, study design and lack of stratification by type and duration of fertility medication use $(8,16)$. Most recent studies and systematic reviews show no overall connection between fertility medication utilization and invasive ovarian cancer when using a subfertile control group or the general population, although some studies finding such an association utilized the general population rather than a subfertile group as controls $(5,6,8,9,11-16)$. Briton et al. (9) and Asante et al. (12) did not demonstrate any link amid fertility treatment and ovarian cancer when using a subfertile control group, even when women had undergone equal or more than four cycles of IVF $(9,12)$. A meta-analysis of multiple cohort research studies including 109,969 patients matched the risk of developing ovarian cancer risk in women undergoing fertility treatment with that in an infertile reference group and the overall population. In comparison with the overall population, the risk of developing ovarian cancer increased considerably for women receiving treatment of fertility issues [relative risk (RR): $1.50,95 \% \mathrm{CI}=1.17-1.92, p<0.05$ ], but similar to that of the infertile reference group (RR: $1.26,95 \%$ $\mathrm{CI}=0.62-2.55, p>0.05)$. The fact that subfertile women possess an inherently overwhelming risk for developing ovarian cancer in contrast to that of the general population, likely explains why a cohort study of parous women found fertility treatment as a substantial threat element for developing ovarian cancer over a 25 -year follow-up [hazard ratio $(\mathrm{HR})=3.9,95 \% \mathrm{CI}=1.2$ 12.6, $p<0.05](5,10)$.

Quite a lot of more recent scholarly works have made efforts to separately stratify for the type of fertility treatment, use of IVF and administration of gonadotropins and/or clomiphene citrate (CC). Those specifically studying women undergoing IVF have generally not found an increased risk in ovarian cancer $(11,13,15)$. One cohort study of 53.859 IVF patients found no association between invasive ovarian cancer and IVF compared to that in the population [standardized incidence ratio $(\mathrm{SIR})=0.96-1.18$, not significant]. Paradoxically, IVF patients had a diminished danger of all cancers $(\mathrm{SIR}=0.78,95 \% \mathrm{CI}=0.73-0.83)$, although a study limitation was the short average follow-up time of only 5 years (13). Another population-focused group research study conducted in Norway about parous women found no noteworthy relationship between ovarian cancer risk and IVF $(\mathrm{HR}=1.56,95 \% \quad \mathrm{CI}=0.94-2.60)$. More significant threats of developing ovarian cancer occurred in patients with IVF who had only had one child but no longer existed after adjusting for multiple comparisons (6). Despite these reassuring findings, two cohort studies show that women failing to conceive after $\mathrm{CC}$ therapy have a heightened threat for developing ovarian cancer, warranting further investigation of this subgroup of women $(14,15)$.

Two recent studies have assessed the threat of developing ovarian cancer in BRCA mutation carriers going through the treatment of fertility issues, since this high-risk group may also be more likely to undergo fertility treatment for fertility preservation or diminished ovarian reserve (17). Both studies are small in size but reassuring $(18,19)$. One cohort study of BRCA mutation carriers' involving 1,073 participants, of which $164(15 \%)$ patients received fertility treatment, showed no association between the treatment of fertility issues and the development of ovarian cancer, regardless of the type of the fertility treatment employed (18). Another harmonized casecontrol research included 941 pairs of BRCA mutation carriers with and without a cancer diagnosis found no substantial connection between the medication of the fertility employed and the succeeding threat of ovarian cancer (19).

Borderline ovarian cancer. According to current literature, the threat of developing borderline ovarian tumors is increased by 


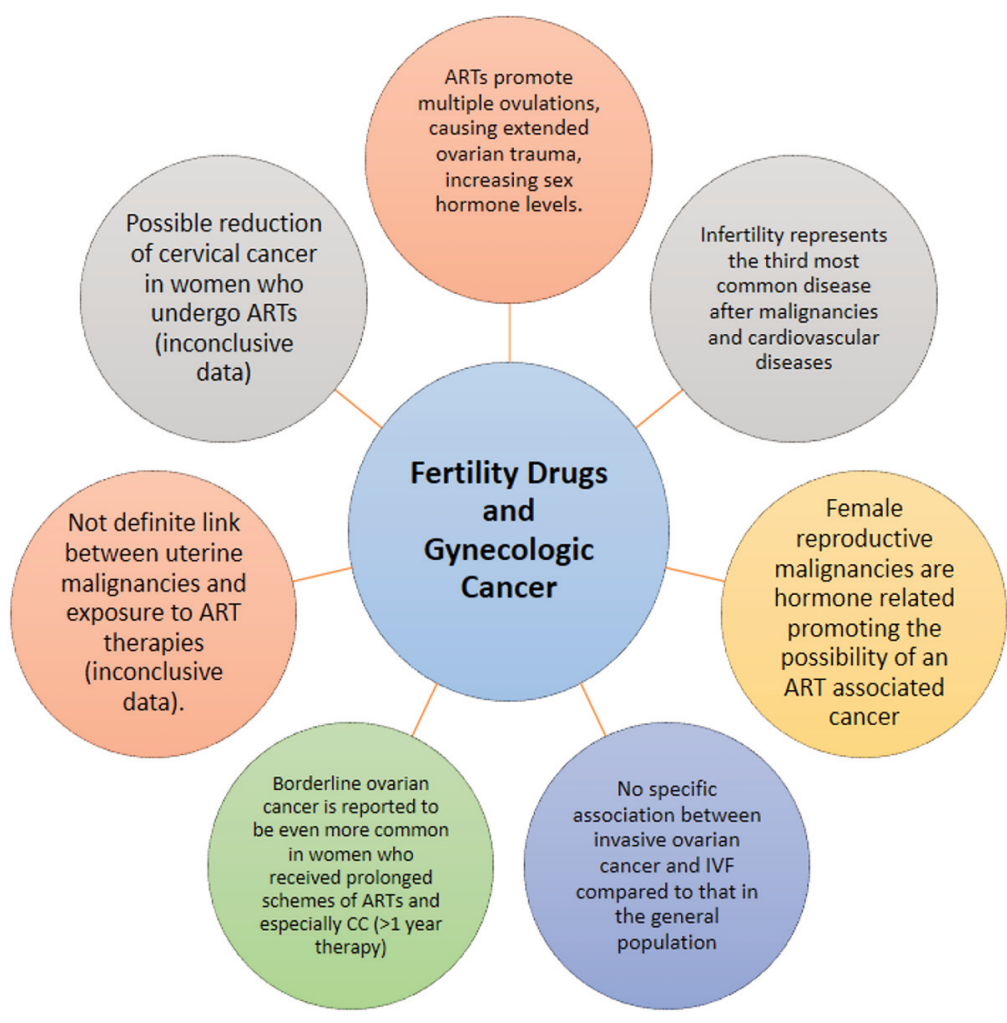

Figure 1. Key points of fertility drugs and gynecologic cancer.

the utilization of gonadotropins as well as $\mathrm{CC}$ by more than three times ( $\mathrm{SIR}=3.61 ; 95 \% \mathrm{CI}=1.45-7.44)$ (10). Similarly, a case-control research, adequately demonstrated the relationship between the utilization of ovulation-inducing medications, specifically hMG and borderline ovarian lumps (20). The analysis of the study results established that the prolonged utilization of the CC to treat infertility heightens the danger of developing borderline tumors. However, the case study also noted that the treatment of infertility problems for less than one year using $\mathrm{CC}$ is not related to the heightened danger for the development of borderline tumors (16). The investigators concluded that the danger to suffer from borderline ovarian cancers was two times greater among the nulliparous females, irrespective of the method employed to treat infertility (21). However, other scholars could not demonstrate such a connection (22). The relationship existing amid the five sets of fertility drugs was examined by another case-control research study encompassing follicle-stimulating hormone, human chorionic gonadotropins, $\mathrm{CC}$, progesterone, gonadotropinreleasing hormone analogs with the borderline ovarian tumors.

The study unearthed the association between the utilization of progesterone and borderline ovarian tumors claiming that the employment of progesterone was associated with the heightened danger to develop borderline ovarian tumors, particularly serous tumors. However, the study found that there was no connection amid the development of borderline ovarian cancers and the utilization of the other various drugs (22). Although the existence of definite agreement still lacks, the debate still continues among various researchers on the connections amid the growth of ovarian tumor and the treatment of fertility issues. Up to date, no conclusive indications to authoritatively demonstrate this relationship exist $(11,23)$. Many studies have propagated the connection amid these medications with the borderline ovarian cancers $(11,20)$.

\section{Uterine Cancer}

Endometrial cancer. Type 1 endometrial cancer is the most prevalent histologic type and is considered hormone dependent, since it is highly correlated with prolonged unopposed estrogen, while progesterone has a protective effect in the endometrium $(2,24)$. Additionally, several conditions which are associated with this specific hormone status, such as polycystic ovarian syndrome (PCOS), obesity, anovulatory cycles and tamoxifen use for breast cancer treatment are well known risk factors for endometrial cancer $(2,3,14)$. 
It seems intuitive that since $\mathrm{CC}$ shares chemical properties with tamoxifen, which has been correlated with an increased risk of cancer in the endometrium, a pathogenetic link between $\mathrm{CC}$ and endometrial cancer could be possible (25, 26). A great number of studies have evaluated this link with contradicting results. Several cohort studies have shown an increase in endometrial cancer rates among patients who were treated with $\mathrm{CC}(10,14,23)$. In a recent registry-based cohort study, the risk was shown to be dose dependent, since the rate of endometrial malignancies was increased among women who have used $\mathrm{CC}$ for more than six cycles $(\mathrm{HR}=4.68,95 \% \mathrm{CI}=1.74-12.6, p=0.011)$ and among the nulliparous patients $(\mathrm{HR}=4.49,95 \% \mathrm{CI}=2.66-7.60 ; p=0.04)$ (14). Nonetheless, in the same study, when women undergoing IVF were compared to the general population, although slightly elevated, no significant difference was found regarding the endometrial cancer rate $(\mathrm{HR}=1.62 ; 95 \%$ $\mathrm{CI}=0.70-3.85, p>0.05)(3,14)$.

Contrarily, the majority of studies have not confirmed these results and have not demonstrated a significantly increased rate of subsequent endometrial cancer in women treated in the past with CC, gonadotropins and $\operatorname{IVF}(24,26)$. In a retrospective follow up study with 12,193 infertile female patients, that were monitored for a very long period of time (26 years), no significant difference was observed regarding the risk of endometrial cancer with gonadotropins $(\mathrm{HR}=1.34$, 95\% CI $=0.76-2.37, p>0.05), \mathrm{CC}(\mathrm{HR}=1.39,95 \% \mathrm{CI}=0.96-$ $2.01, p>0.05)$, or both $(\mathrm{HR}=1.77,95 \% \mathrm{CI}=0.98-3.19, p>0.05)$ compared to control group of women non-users (27). Another cohort study that lasted for 30 years and incorporated 2,431 women diagnosed with infertility, found that the risk of endometrial cancer was significantly increased in women treated with $\mathrm{CC}$ and human menopausal gonadotropin (hMG) compared to the general population $(\mathrm{SIR}=5.0,95 \% \mathrm{CI}=2.15-$ $9.85, p<0.05)$, but no such association was confirmed in the subsequent multivariable analysis (23). Furthermore, according to large cohort study with 29,700 women, the incidence of uterine cancer was not found higher than expected in women exposed to IVF treatment versus untreated infertile women ( $\mathrm{SIR}=1.09,95 \% \mathrm{CI}=0.45-2.61, p>0.05)$ (28). The safety of IVF has been demonstrated by another cohort study with 19,000 women, in which after a follow up period of 17 years after treatment, the endometrial cancer risk was comparable after ovarian stimulation with IVF protocols versus other fertility treatment approaches $(\mathrm{SIR}=1.41 ; 95 \%$ $\mathrm{CI}=0.77-2.37, p>0.05)(29)$.

Nevertheless, it has been argued that, the fact that in most studies the control group consists of the general population can constitute a huge bias, since only the study group is imposed to the effect of subfertility. Hence, it would be more accurate to compare infertile women which are subjected to fertility treatment with infertile patients that do not try to conceive, as the control group $(5,26)$. Therefore, meta- analysis from 15 studies that utilized the general population as the control group have demonstrated a 1.8 -fold increased risk of endometrial cancer in 1,7 million participants that were exposed to any infertility drugs (26). On the other hand, in the same systematic review, when the study group (156,774 participants) were compared to an untreated infertility cohort (six studies), no definite link between uterine malignancy and exposure to any drug was recorded $(\mathrm{RR}=0.96,95 \% \mathrm{CI}=0.67-1.37, p>0.05)$ (26). Finally, another meta-analysis of five studies, which included 776,224 infertile women, found no increased risk of endometrial carcinomatosis between treatment and nontreatment infertility groups $(\mathrm{OR}=0.78,95 \% \mathrm{CI}=0.39-1.57, p>0.05)$; the authors even suggested that fertility drugs may reduce the incidence of uterine cancer from 2.22 to $0.14 \%$. The researchers reached the same results when the role of IVF treatment was exclusively investigated, concluding that the incidence of uterine cancer was statistically decreased after IVF protocols $(\mathrm{OR}=0.38 ; 95 \% \mathrm{CI}=0.30-0.47, p<0.05)(30)$.

Cervical cancer. The research examination of about 8,422 women from 1965 until 1988 revealed that the threat of cervical cancer prevalence is not altered by the infertility treatment drugs (31). Similar views have been reported by a cohort study, which claims that ovulation induction considerably decreases the danger of cervical cancer (25). A reduction in the risk of developing cervical cancer for individuals going through IVF treatment is conveyed by other similar cohort studies, and despite that the mechanism behind this phenomenon remains unclear, perhaps is related to the better access to medical care with more frequent cervical cytology screening in women undergoing fertility treatment $(9,32)$.

\section{Discussion}

The health-related safety of the ovulation-inducing drugs, as well as the dangers connected to their utilization, have attracted increased interest among scholars in the past three decades. This is owing to the fact that the medications employed for ovulation induction during IVF such as $\mathrm{rFSH}, \mathrm{hCG}$, and hMG, proliferate the levels of gonadal hormones. This has contributed to the intensification of the concerns about the risk of developing cancer in endometrium, breast, ovary, as well as other vulnerable and sensitive organs $(10,32)$.

Intensive ovulation induction treatment is accomplished through the utilization of multiple folliculogenesis during IVF treatment. Retrieval of the oocytes is achieved through the puncture of the ovarian follicles (33). In some studies, the interventions of ovarian puncture and ovulation induction, were connected with the progression of ovarian cancer. However, other studies dissociated the two inventions with ovarian cancer development $(9,10,19)$. The biological confirmations reiterate 


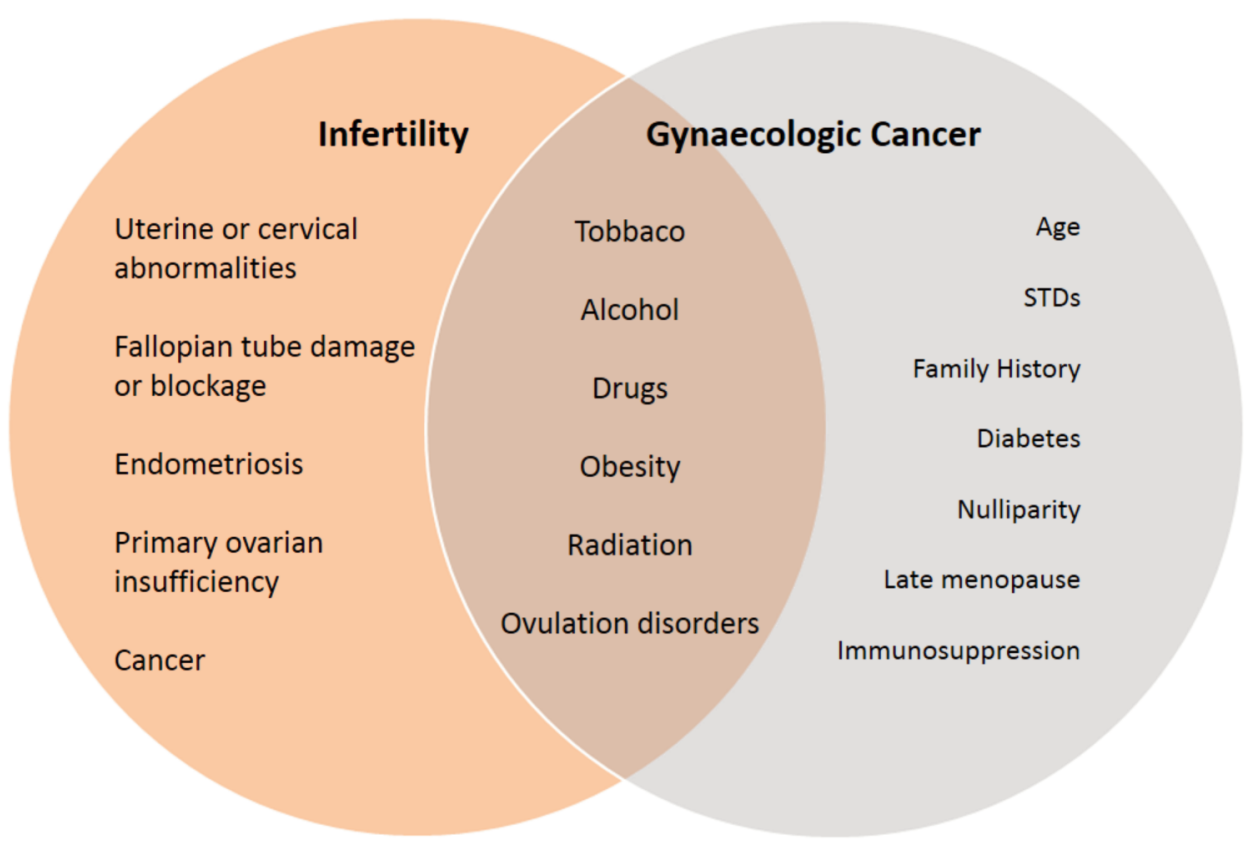

Figure 2. Main risk factors and their associations between infertility and gynecologic cancer.

the likelihood of the extensive relationship amid the ovarian cancer progression and the exposure to ovulation-induction medications, owing to the fact that associated change in endogenous hormones, as well as the "incessant ovulation" throughout the procreative ages, are acceptable justifications for numerous aspects that change ovarian cancer risk. Furthermore, because one probability is that the utilization of contraceptive drugs can decrease the danger of developing ovarian cancer, women that reduced the utilization of oral contraceptives in couples that are not fertile can potentially lead to heightened dangers for developing ovarian cancer $(34,35)$.

As far as endometrial cancer is concerned, taking into consideration its hormonal susceptibility, it is logical and justifiable to suggest that fertility medication through ovarian stimulation could increase the incidence of this malignancy (2, 4). Conversely, some could argue that fertility drugs could decrease the risk of endometrial cancer due to the protective effect of the progesterone that takes place secondarily with ovulation (24). Several studies have investigated this plausible relationship, but most of them are limited by low quality of evidence since they are non-randomized and by methodological issues and specifically a short or incomplete follow-up period, a small sample size and different confounding factors such as PCOS and obesity that are independently linked to carcinomatosis $(3,5,24)$. In addition, many of the studies evaluate subfertile populations before IVF was established as a common treatment modality, thus, their outcomes do not reflect the current practice patterns (24).
Several studies have suggested that multiple cycles, as well as high doses of CC may be related to an increased risk of uterine malignancies. Nonetheless, the evidence for this argument remains inconclusive since they are not consistently reproduced through different studies. Moreover, the suggestion of them being an independent risk factor of cancer is very difficult to be undoubtedly confirmed (4). Furthermore, the inconsistency of the results, from studies conducted in the past, reveal the importance of using an infertile group of women not treated with fertility drugs, as the control group in the various comparisons which are investigated. This could offer a better adjustment regarding the preexisting risk factors for uterine cancer that may simultaneously exist in subfertile patients (3) (Figure 2).

Nevertheless, most of the existing meta-analysis and studies, despite being mainly retrospective and cohort have demonstrated the safety of different fertility treatment options. The incidence of uterine cancer is not altered in infertile patients treated with CC only, CC and hMG or hMG alone, in comparison to the non-fertility treatment group. Even further, a possible protective role of fertility medication has been documented regarding the risk of uterine cancer, when patients that have been subjected to IVF are evaluated (30). Therefore, according to the guidelines issued by the Practice Committee of the American Society for Reproductive Medicine (ASRM) in 2016 (Summary Statement - Grade B), the evidence are adequate to support 
the suggestion that fertility drugs are not directly related to an increased risk of endometrial cancer (24).

\section{Conclusion}

In this review we tried to investigate the possible role of fertility medications and ARTs to subsequent carcinogenesis in infertile women. Despite the fact that this relationship seems theoretically plausible, many factors are simultaneously and independently present in both of these conditions (infertility and cancer), such as anovulation, smoking, nulliparity and obesity. Several studies have tried to determine the exact association of these two entities; however, the data remain limited since most research derives from observational cohorts or meta-analyses. Furthermore, most of the existing studies suffer from methodological issues, including shortterm follow-up periods, small sample sizes, different treatment protocols and lack of controls over confounding factors.

Although no definite answer has been given, ARTs should be considered relatively safe regarding their subsequent risk of carcinogenesis. Additionally, despite the lack of high quality evidence for the absolute safety of these drugs, and even given the possibility of a modest increase in the incidence of ovarian or endometrial cancer many years after their use, the risk of their utilization may be justifiable considering the great desire of a woman to conceive and give birth to her own child. Nevertheless, more high-quality research is required in the future, for definite conclusions to be made. Until then, precautions should be taken, and the use of these hormone-dependent drugs should be individualized based on the needs of each woman.

\section{Conflicts of Interest}

The Authors declare that they have no competing interests.

\section{Authors' Contributions}

T.G, K.A, F.Z, T.N and K.N.E. contributed to conception and design. A.K, D.M, K.N.E and S.A. were responsible for overall supervision. K.A, K.M, T.G and G.N drafted the manuscript, which was revised by G.N. All authors read and approved the final manuscript.

\section{References}

1 Momenimovahed Z, Taheri S, Tiznobaik A and Salehiniya H: Do the fertility drugs increase the risk of cancer? A review study. Front Endocrinol (Lausanne) 10: 313, 2019. PMID: 31191449. DOI: $10.3389 /$ fendo.2019.00313

2 Del Pup L, Peccatori FA, Levi-Setti PE, Codacci-Pisanelli G and Patrizio P: Risk of cancer after assisted reproduction: A review of the available evidences and guidance to fertility counselors. Eur Rev Med Pharmacol Sci 22(22): 8042-8059, 2018. PMID: 30536354. DOI: $10.26355 /$ eurrev_201811_16434
3 Kroener L, Dumesic D and Al-Safi Z: Use of fertility medications and cancer risk: A review and update. Curr Opin Obstet Gynecol 29(4): 195-201, 2017. PMID: 28538003. DOI: 10.1097/GCO.0000000000000370

4 Louis LS, Saso S, Ghaem-Maghami S, Abdalla Hand Smith JR: The relationship between infertility treatment and cancer including gynaecological cancers. Obstetr Gynaecol 15: 177183, 2013. DOI:10.1111/tog. 12040

5 Siristatidis C, Sergentanis TN, Kanavidis P, Trivella M, Sotiraki M, Mavromatis I, Psaltopoulou T, Skalkidou A and Petridou ET: Controlled ovarian hyperstimulation for IVF: Impact on ovarian, endometrial and cervical cancer-a systematic review and metaanalysis. Hum Reprod Update 19(2): 105-123, 2013. PMID: 23255514. DOI: 10.1093/humupd/dms051

6 Reigstad MM, Larsen IK, Myklebust TÅ, Robsahm TE, Oldereid NB, Omland AK, Vangen S, Brinton LA and Storeng R: Cancer risk among parous women following assisted reproductive technology. Hum Reprod 30(8): 1952-1963, 2015. PMID: 26113657. DOI: 10.1093/humrep/dev124

7 Katzke VA, Kaaks R and Kühn T: Lifestyle and cancer risk. Cancer J 21(2): 104-110, 2015. PMID: 25815850. DOI: 10.1097/PPO.0000000000000101

8 Whittemore AS, Harris R and Itnyre J: Characteristics relating to ovarian cancer risk: Collaborative analysis of 12 US casecontrol studies. II. Invasive epithelial ovarian cancers in white women. Collaborative Ovarian Cancer Group. Am J Epidemiol 136(10): 1184-1203, 1992. PMID: 1476141. DOI: 10.1093/ oxfordjournals.aje.a116427

9 Brinton LA, Trabert B, Shalev V, Lunenfeld E, Sella T and Chodick G: In vitro fertilization and risk of breast and gynecologic cancers: A retrospective cohort study within the Israeli Maccabi healthcare services. Fertil Steril 99(5): 11891196, 2013. PMID: 23375197. DOI: 10.1016/j.fertnstert. 2012.12.029

10 Kessous R, Davidson E, Meirovitz M, Sergienko R and Sheiner $\mathrm{E}$ : The risk of female malignancies after fertility treatments: A cohort study with 25-year follow-up. J Cancer Res Clin Oncol 142(1): 287-293, 2016. PMID: 26337160. DOI: 10.1007/s00432015-2035-x

11 van Leeuwen FE, Klip H, Mooij TM, van de Swaluw AM, Lambalk CB, Kortman M, Laven JS, Jansen CA, Helmerhorst FM, Cohlen BJ, Willemsen WN, Smeenk JM, Simons AH, van der Veen F, Evers JL, van Dop PA, Macklon NS and Burger CW: Risk of borderline and invasive ovarian tumours after ovarian stimulation for in vitro fertilization in a large Dutch cohort. Hum Reprod 26(12): 3456-3465, 2011. PMID: 22031719. DOI: 10.1093/humrep/der322

12 Asante A, Leonard PH, Weaver AL, Goode EL, Jensen JR, Stewart EA and Coddington CC: Fertility drug use and the risk of ovarian tumors in infertile women: A case-control study. Fertil Steril 99(7): 2031-2036, 2013. PMID: 23552324. DOI: 10.1016/j.fertnstert.2013.02.010

13 Luke B, Brown MB, Spector LG, Missmer SA, Leach RE, Williams M, Koch L, Smith Y, Stern JE, Ball GD and Schymura MJ: Cancer in women after assisted reproductive technology. Fertil Steril 104(5): 1218-1226, 2015. PMID: 26271227. DOI: 10.1016/j.fertnstert.2015.07.1135

14 Reigstad MM, Storeng R, Myklebust TÅ, Oldereid NB, Omland AK, Robsahm TE, Brinton LA, Vangen S, Furu K and Larsen IK: Cancer risk in women treated with fertility drugs according 
to parity status-a registry-based cohort study. Cancer Epidemiol Biomarkers Prev 26(6): 953-962, 2017. PMID: 28108444. DOI: 10.1158/1055-9965.EPI-16-0809

15 Trabert B, Lamb EJ, Scoccia B, Moghissi KS, Westhoff CL, Niwa $S$ and Brinton LA: Ovulation-inducing drugs and ovarian cancer risk: Results from an extended follow-up of a large United States infertility cohort. Fertil Steril 100(6): 1660-1666, 2013. PMID: 24011610. DOI: 10.1016/j.fertnstert.2013.08.008

16 Rossing MA, Daling JR, Weiss NS, Moore DE and Self SG: Ovarian tumors in a cohort of infertile women. $\mathrm{N}$ Engl $\mathrm{J}$ Med 331(12): 771-776, 1994. PMID: 8065405. DOI: 10.1056/NEJM1 99409223311204

17 Wang ET, Pisarska MD, Bresee C, Chen YD, Lester J, Afshar Y, Alexander C and Karlan BY: BRCA1 germline mutations may be associated with reduced ovarian reserve. Fertil Steril 102(6): 1723-1728, 2014. PMID: 25256924. DOI: 10.1016/j.fertnstert. 2014.08.014

18 Perri T, Lifshitz D, Sadetzki S, Oberman B, Meirow D, BenBaruch G, Friedman E and Korach J: Fertility treatments and invasive epithelial ovarian cancer risk in Jewish Israeli BRCA1 or BRCA2 mutation carriers. Fertil Steril 103(5): 1305-1312, 2015. PMID: 25792249. DOI: 10.1016/j.fertnstert.2015.02.011

19 Gronwald J, Glass K, Rosen B, Karlan B, Tung N, Neuhausen SL, Moller P, Ainsworth P, Sun P, Narod SA, Lubinski J, Kotsopoulos $\mathrm{J}$ and Hereditary Breast Cancer Clinical Study Group: Treatment of infertility does not increase the risk of ovarian cancer among women with a BRCA1 or BRCA2 mutation. Fertil Steril 105(3): 781-785, 2016. PMID: 26698676. DOI: $10.1016 /$ j.fertnstert.2015.11.034

20 Shushan A, Paltiel O, Iscovich J, Elchalal U, Peretz T and Schenker JG: Human menopausal gonadotropin and the risk of epithelial ovarian cancer. Fertil Steril 65(1): 13-18, 1996. PMID: 8557128.

21 Mosgaard BJ, Lidegaard O, Kjaer SK, Schou G and Andersen AN: Ovarian stimulation and borderline ovarian tumors: A casecontrol study. Fertil Steril 70(6): 1049-1055, 1998. PMID: 9848294. DOI: 10.1016/s0015-0282(98)00337-9

22 Bjørnholt SM, Kjaer SK, Nielsen TS and Jensen A: Risk for borderline ovarian tumours after exposure to fertility drugs: Results of a population-based cohort study. Hum Reprod 30(1): 222-231, 2015. PMID: 25376453. DOI: 10.1093/humrep/deu297

23 Lerner-Geva L, Rabinovici J, Olmer L, Blumstein T, Mashiach $\mathrm{S}$ and Lunenfeld B: Are infertility treatments a potential risk factor for cancer development? Perspective of 30 years of follow-up. Gynecol Endocrinol 28(10): 809-814, 2012. PMID: 22475084. DOI: $10.3109 / 09513590.2012 .671391$

24 Practice Committee of the American Society for Reproductive Medicine: Fertility drugs and cancer: A guideline. Fertil Steril 106(7): 1617-1626, 2016. PMID: 27573989. DOI: 10.1016/ j.fertnstert.2016.08.035

25 Silva Idos S, Wark PA, McCormack VA, Mayer D, Overton C, Little V, Nieto J, Hardiman P, Davies M and MacLean AB: Ovulation-stimulation drugs and cancer risks: A long-term follow-up of a British cohort. Br J Cancer 100(11): 1824-1831, 2009. PMID: 19436296. DOI: 10.1038/sj.bjc.6605086
26 Skalkidou A, Sergentanis TN, Gialamas SP, Georgakis MK, Psaltopoulou T, Trivella M, Siristatidis CS, Evangelou E and Petridou E: Risk of endometrial cancer in women treated with ovary-stimulating drugs for subfertility. Cochrane Database Syst Rev 3: CD010931, 2017. PMID: 28349511. DOI: 10.1002/ 14651858.CD010931.pub2

27 Brinton LA, Westhoff CL, Scoccia B, Lamb EJ, Trabert B, Niwa $\mathrm{S}$ and Moghissi KS: Fertility drugs and endometrial cancer risk: Results from an extended follow-up of a large infertility cohort. Hum Reprod 28(10): 2813-2821, 2013. PMID: 23943795. DOI: 10.1093/humrep/det323

28 Venn A, Watson L, Bruinsma F, Giles G and Healy D: Risk of cancer after use of fertility drugs with in-vitro fertilisation. Lancet 354(9190): 1586-1590, 1999. PMID: 10560672. DOI: 10.1016/S0140-6736(99)05203-4

29 Del Pup L, Peccatori FA, Levi-Setti PE, Codacci-Pisanelli G and Patrizio P: Risk of cancer after assisted reproduction: A review of the available evidences and guidance to fertility counselors. Eur Rev Med Pharmacol Sci 22(22): 8042-8059, 2018. PMID: 30536354. DOI: 10.26355/eurrev_201811_16434

30 Saso S, Louis LS, Doctor F, Hamed AH, Chatterjee J, Yazbek J, Bora S, Abdalla H, Ghaem-Maghami S and Thum MY: Does fertility treatment increase the risk of uterine cancer? A metaanalysis. Eur J Obstet Gynecol Reprod Biol 195: 52-60, 2015. PMID: 26476799. DOI: 10.1016/j.ejogrb.2015.09.002

31 Althuis MD, Scoccia B, Lamb EJ, Moghissi KS, Westhoff CL, Mabie JE and Brinton LA: Melanoma, thyroid, cervical, and colon cancer risk after use of fertility drugs. Am J Obstet Gynecol 193(3 Pt 1): 668-674, 2005. PMID: 16150258. DOI: 10.1016/j.ajog.2005.01.091

32 Dor J, Lerner-Geva L, Rabinovici J, Chetrit A, Levran D, Lunenfeld B, Mashiach S and Modan B: Cancer incidence in a cohort of infertile women who underwent in vitro fertilization. Fertil Steril 77(2): 324-327, 2002. PMID: 11821091. DOI: 10.1016/s0015-0282(01)02986-7

33 Fanchin R, Righini C, Olivennes F, Taylor S, de Ziegler D and Frydman R: Uterine contractions at the time of embryo transfer alter pregnancy rates after in vitro fertilization. Hum Reprod 13(7): 1968-1974, 1998. PMID: 9740459. DOI: 10.1093/ humrep/13.7.1968

34 Holschneider CH and Berek JS: Ovarian cancer: Epidemiology, biology, and prognostic factors. Semin Surg Oncol 19(1): 3-10, 2000. PMID: 10883018. DOI: 10.1002/1098-2388(200007/ 08) $19: 1<3:$ :aid-ssu2>3.0.co;2-s

35 Smith ER and Xu XX: Ovarian ageing, follicle depletion, and cancer: A hypothesis for the aetiology of epithelial ovarian cancer involving follicle depletion. Lancet Oncol 9(11): 11081111, 2008. PMID: 19012860. DOI: 10.1016/S1470-2045(08) 70281-X

Received February 1, 2021

Revised March 2, 2021

Accepted March 5, 2021 